\title{
Corrective Action Management (CAM) Process Guide
}

T. M. Lutter

Date Published

June 1996

Prepared for the U.S. Department of Energy

Assistant Secretary for Environmental Management

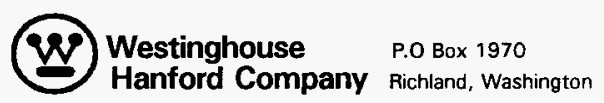

Management and Operations Contractior for the

U.S. Department of Energy under Contract DE-AC06-87RL10930

Approved for public release; distribution is unlimited 


\section{ODEEINTENTIONALLY LEFT BLANK.}




\section{RELEASE AUTHORIZATION}

Document Number:

Document Title:

Release Date: $06 / 18 / 96$

This document was reviewed following the procedures described in WHC-CM-3-4 and is:

APPROVED FOR PUBLIC RELEASE

Whe Information Release Administration specialist: V. L. Butclend

v. L. Birkland
$6 / 18 / 96$ 
INIO TrGE INTENTIUNALLY LEFT BLANK. 
WHC-EP-0907 REV. 0

\section{CORRECTIVE ACTION MANAGEMENT (CAM) PROCESS GUIDE}


THGSPAGE INTENTIUNALLYY

LEFT BLANK. 


\section{WHC-EP-0907 REV. 0}

\section{Transition Item 3.5.1.1.4, Hanford Action Tracking System \\ Pre-Award Action}

1. Publish a HATS/Corrective Action Management Process Guide to define business rules and user responsibilities 
THISPAGE IRTENTIUIVALY LEFT BLANK. 


\section{Table of Contents}

1.0 INTRODUCTION

3.0 BUSINESS RULES, HATS, AND PROCESS FLOW . . . . . . . . . . Page 4

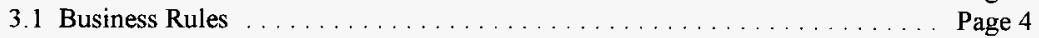

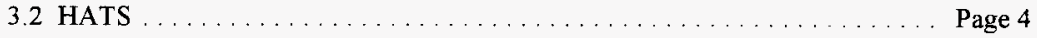

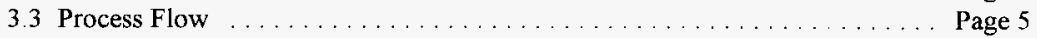

3.3 .1 Assessment Conducted $\ldots \ldots \ldots \ldots \ldots \ldots \ldots$ Page 6

3.3.2 Conditions Identified and Acknowledged . . . . . . . . . . Page 6

3.3.3 Contractor Organization Identified . . . . . . . . . . . . . . Page 7

3.3.4 Condition Evaluated and Assigned $\ldots \ldots \ldots \ldots \ldots$ Page 7

3.3.5 Corrective Action Plan Established . . . . . . . . . . . . . Page 7

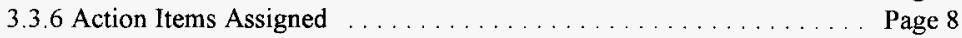

3.3.7 Condition Reports and Closure $\ldots \ldots \ldots \ldots \ldots$ Page 8

4.0 REFERENCE DOCUMENTS $\ldots \ldots \ldots \ldots \ldots \ldots \ldots \ldots \ldots \ldots$ Page 10

Figures

Figure 1 Site CAM Infrastructure and Relationships $\ldots \ldots \ldots \ldots \ldots \ldots$ Page 3

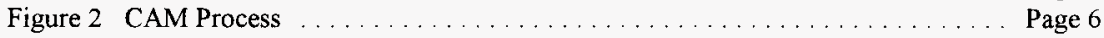

\section{Appendices}

Appendix A Definitions for: Commitment Tracking

Appendix B HATS Quick Reference Guide

Appendix C Representative Listing of Implementing Procedures

Appendix D Required Fields for HATS Document 
IE MTENIUUVALLYY LEFTBLANK. 


\section{WHC-EP-0907 REV.0 \\ CORRECTIVE ACTION MANAGEMENT (CAM) PROCESS GUIDE}

\subsection{ENTRODUCTION}

Consistent direction for identification, long-term reporting and trending, and correction of conditions adverse to the environment, safety, and health will facilitate a successful transition and follow-on for the Project Hanford Management Contractor (PHMC). Continuity of the corrective action management process is vital. It provides consistency via reporting and trending on corrective action management activities at the Site during the transition process. To ensure success, consideration of the business rules and the Hanford Action Tracking System (HATS), the automated tool, that supports them, is essential. This documents provides a consolidated synopsis of corrective action management business rules, the process, and the HATS to support the transition process at Hanford. It applies to the baseline of corrective action work the PHMC and its subcontractors will inherit.

HATS satisfies the requirement for collection of data that enables long-term reporting and trending. The information contains all originating document, condition, and action data. HATS facilitates consistent tracking, reporting, closure, and trending of the corrective action work in progress across the Site. HATS follows the glossary standard definitions for commitment tracking listed in Appendix A and Site data value standards that are applicable.

For long term access and use, HATS data are fed to a full text search and retrieval system called Search Hanford Accessible Reports Electronically (SHARE). An individual, organization, or company has the ability, through SHARE, to pull together the appropriate information as needed.

\subsection{ROLES AND RESPONSIBILITIES}

There are two types of responsibilities that govern corrective action management relationships at the Site: 1) Site policy and operations and 2) Company policy and operations. The infrastructure that supports the two governing areas, policy and operations, is depicted in Figure 1. The dashed lines represent entities or direction that currently does not exist. For productive interaction, all the entities must be present and fully functional

The first area deals with Site-wide policy. Site-wide policy is set by the U.S. Department of Energy, Richland Operations Office (RL) program managers and disseminated to the main contractors. The policy provides direction governing the corrective action management business rules and Site workflow process.

The next area covers each company's policy developed from the Site policy. Each company's policy interprets, adapts, and implements the Site policy to demonstrate compliance. It is critical to the success of the Site for all contractors to follow a cohesive and consistent direction that represent a core set of business rules. This commonality contributes to congruous information provided to RL. It enables compiling a Site representation and status of the progress and condition of corrective actions. 


\section{WHC-EP-0907 REV.0 \\ CORRECTIVE ACTION MANAGEMENT (CAM) PROCESS GUIDE}

Currently the Westinghouse Hanford Company (WHC) Corrective Action Management (CAM) Board disseminates Site policy to the rest of WHC organizations by means of WHCCM-1-4 procedure manual. The other contractors have individuals distribute Site policy within their respective companies.

Figure 1 Site CAM Infrastructure and Relationships

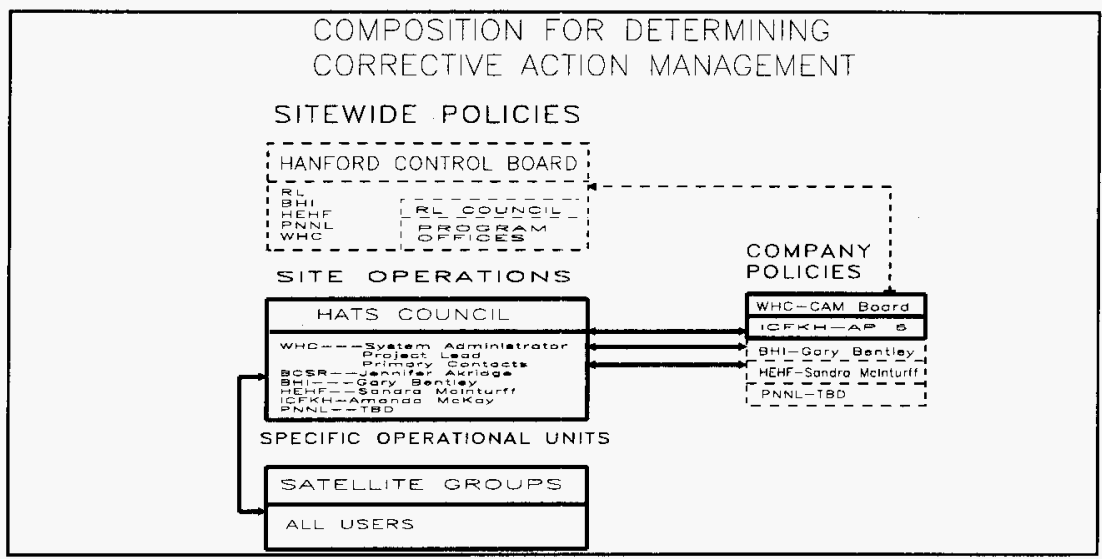

Third and most critical, Site operations, through the HATS Council, cultivate a teaming environment promoting the dialogue and interaction across contractors and organizations. Site operation is the implementation mechanism of each company's policy covering CAM compliance. The multicontractor and multiorganizational setting requires core business rules to be applied with the same consistency in order to provide a more complete picture to RL. The HATS Council is the vital link that ties Site operations, company policy, and specific operational units together. Currently, Pacific Northwest National Laboratory (PNNL) is the only contractor not represented on the HATS Council.

Specific operational units function at the facility complex level through established satellite groups. They interact directly with the HATS Council providing feedback to ensure consideration in practical application of the day-to-day work. They are formed as needed. 


\section{CORRECTIVE ACTION MANAGEMENT (CAM) PROCESS GUIDE}

\subsection{BUSINESS RULES, HATS, AND PROCESS FLOW}

\subsection{Business Rules}

The following are representative of the business rules that established an environment to effectively perform CAM work consistently across the Site:

- Provide the appropriate structure that satisfies and implements compliance to external and internal drivers;

- Place the corrective action operations and data at the appropriate organizational ownership level;

- RL will jdentify closure authority and notify the contractor after the assessment is conducted and prior to commencement of the work;

- Track from identification through completion of adverse conditions that require corrective action;

- Identify the root cause for each adverse condition;

- Implement a graded approach to determine the extent of the required corrective action for each adverse condition risk value;

- $\quad$ Retain the "as-found" risk value of a condition along with the "as-is" risk value for a condition throughout the correction process;

- Analyze CAM data to identify trends impacting quality, identify opportunity improvements, and process improvements;

- Perform analysis to determine if the circumstances that caused a condition can be identified, avoided, or prevented in other areas;

- Establish consistent operational procedures across facility complexes; and

- Advocate self-identification and tracking of more than adverse conditions to enable a truer picture of work in progress.

\subsection{HATS}

HATS is the automated tool that supports the business rules and the process of CAM. The HATS Quick Reference Guide is attached as Appendix B for general information. The application is a concurrent multiuser and multicontractor application in a client server distributed environment. This means that it can be accessed by many users at the same time from many 


\section{WHC-EP-0907 REV.0 \\ CORRECTIVE ACTION MANAGEMENT (CAM) PROCESS GUIDE}

different locations. The application encompasses the process business rules. The following * business rules are representative of HATS' overall capabilities:

- $\quad$ Provide a single access point for CAM documents and data;

- $\quad$ Provide users with the functionality of a graded approach methodology to perform a risk value analysis (e.g., priority planning grid);

- $\quad$ Provide users with a module to perform simple trending;

- $\quad$ Provide users with a module to facilitate root cause analysis;

- Minimize manual interfaces and duplicate data entry by establishing automated interfaces with appropriate systems;

- $\quad$ Provide traceability to support system and data change control;

- Provide a tool and report generator that allows originators to collect and report on their assessments from detail to global levels;

- Enable user level adhoc reporting capabilities;

- Support tracking and statusing of non-CAM work enabling a more complete view of related work scope;

- Support common and specific operations across facility complexes;

- Standardize data entry, reporting, accesses, closure, and configuration management of data;

- Standardize notification process using the electronic mail utility upon entry of new items or status changes;

- Provide initial security to the system using passwords; and

- Provide security to the data based on role, view code, and contractor.

\subsection{Process Flow}

The process flow for CAM is depicted in Figure 2. It identifies the life-cycle for processing conditions that are noncompliant with applicable Federal and non-Federal environmental, safety, and health laws; internal and external regulations; as well as contractual requirements commensurate with the risk of health, safety, and environmental harm. Reporting is required throughout the process. 
eıp WVD

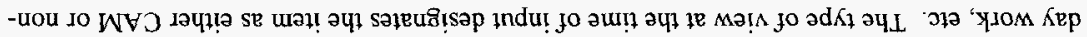

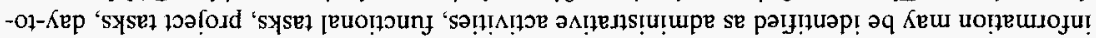

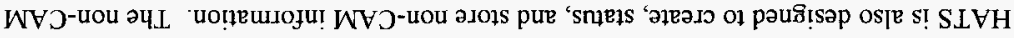

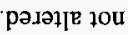

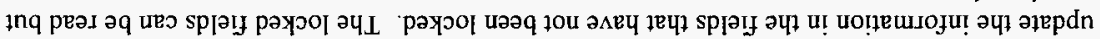

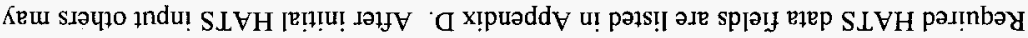

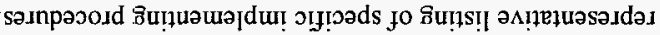

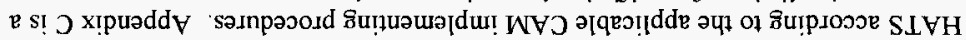

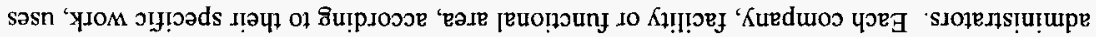

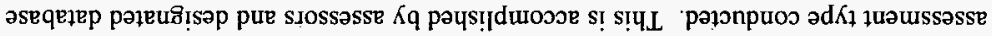
әЧฺ

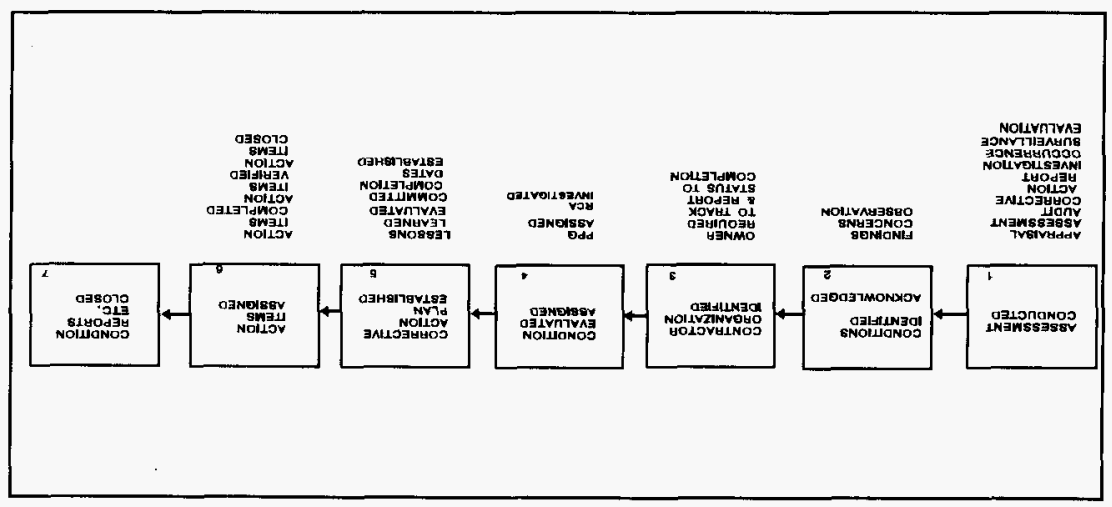

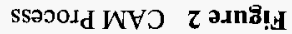

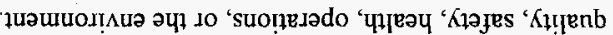

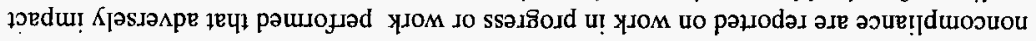

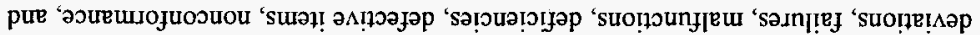

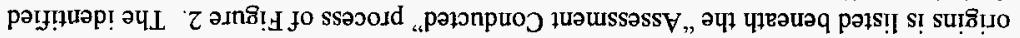

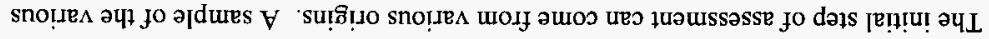

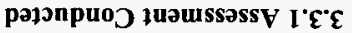




\section{WHC-EP-0907 REV.0 \\ CORRECTIVE ACTION MANAGEMENT (CAM) PROCESS GUIDE}

\subsubsection{Conditions Identified and Acknowledged}

The "Conditions Identified and Acknowledged" process of Figure 2 suggests that any employee, agency, or organization can identify deviations, failures, malfunctions, deficiencies, defective items, nonconformances, and noncompliance on work in progress and work performed Closure authority is determined at this point. A meeting is conducted to formulate a mutual understanding and agreement between the condition identifier and the potential condition owner regarding the condition and its validity before any corrective action work can begin.

For CAM items all of the condition information and meeting results can be kept in HATS as a chronicle of events prior to initiation of the work. The designated database administrators perform the data entry.

For non-CAM items, administrative activities and their associated information can be set up and input for statusing and tracking. The administrative activities are set up with fewer restrictions than CAM tasks

HATS and the electronic mail utility are integrated to provide a real-time notification, alerting a person they have been identified as the condition owner. This applies to CAM and non-CAM items that have been entered into the system.

\subsubsection{Contractor Organization Identified}

The assigned company or organization is responsible for initiating and implementing measures to correct the condition as depicted in the "Contractor Organization Identified" process in Figure 2. This can be accomplished by a single individual or a group of individuals. They are required to track and report status throughout the life-cycle of a condition and associated corrective actions.

Within HATS, all information associated with the party responsible for correcting the adverse condition or performing the administrative activities can be entered. The initial input is done at the "condition document" screen.

\subsubsection{Condition Evaluated and Assigned}

A graded-approach method is applied as determined by the responsible contractor. This is indicated in "Condition Evaluated and Assigned" process in Figure 2. It is applied to the condition and assesses the following: risk value, priority, rigor of analysis, and the extent of follow-up to the identified condition. The root cause analysis is determined prior to the development of a corrective action plan. The corrective action(s) required is commensurate with the assigned risk value. The assigned risk value is one of the factors to determine the appropriate closure authority.

The graded-approach method and root cause analysis are required for CAM related work only. It is not necessary for non-CAM administrative activities within HATS. 


\subsubsection{Corrective Action Plan Established}

The development, review, and implementation of a corrective action plan are accomplished by the condition/issue owner. The plan documents the steps and actions required to correct conditions or issues and prevent or minimize recurrence. It is the basis for correcting an adverse condition, and may also include "lessons learned" and commitment date information.

Corrective action plans are documented in HATS for identified adverse conditions. The information within HATS includes root cause analysis data, root cause codes, completion dates, assessed risk value, person responsible for the action(s), contingencies, etc. Lessons learned information is contained within a separate database.

In the non-CAM portion of HATS, administrative activities do not require a corrective action plan. The administrative activities pertain to routine work in progress.

\subsubsection{Action Items Assigned}

The responsibility of the action items is primarily assigned to the organization accountable for the condition. All assigned action items must be completed, verified, and closed before the condition is closed out. Cooperation and assistance from other organizations and/or contractors may be required to correct a condition. In the event of an organizational or a company change, the current senior level manager retains the responsibility for the existing work in progress until reassignment of the work can be determined and agreed upon among the parties involved.

Once the person responsible for the action is identified and entered in HATS, an automatic notification is sent to that person. It alerts a person to the new assignment via electronic mail. The individual is does not have to enter the database to know he/she has been identified as the owner of the condition. It will also send a notification when the action is reassigned to another. The notification information states whether it is assigned or reassigned and displays the action title.

\subsubsection{Condition Reports and Closure}

Status reporting is required throughout the entire CAM process. The reporting provides an indication of the progress, adjusted dates and schedules, and a chronology of events leading to the closure of the condition. As stated previously, the assigned risk value is a factor in determining the appropriate closure authority. The closure authority is identified and documented early in the process by RL. Once this is established and all the action items related to the condition are complete, closure documentation is prepared, approved, and filed completing the final step in the corrective action process life-cycle.

HATS provides standard and ad hoc reporting capabilities for CAM and non-CAM items. Within the standard reports, detail and summary levels are available. Ad hoc capabilities provide users with the ability to generate specific reports. Trend analysis reports by cause code, 
WHC-EP-0907 REV.0

\section{CORRECTIVE ACTION MANAGEMENT (CAM) PROCESS GUIDE}

organization delinquency rates, and others, can be generated provided codes were entered in HATS. Line graphs and bar charts can be produced from the report data.

HATS provides a field for identified closure authority person. The closure authority is established at the time the responsible contractor is identified as implied in Box 3 of Figure 2 The condition owner is identified later in the CAM process. HATS provides the capability to input information that supports closure of conditions and actions. 


\subsection{REFERENCE DOCUMENTS}

10 CFR PART 830, 1994, Nuclear Safety Management, Code of Federal Regulations, as amended.

DOE, 1991, Quality Assurance, DOE Order 5700.6C, U.S. Department of Energy, Washington, D. C.

DOE-RL, 1996, Project Hanford Management Contract, Section H, DE-RP06-96RL13200, U.S. Department of Energy, Richland Operations Office, Richland, Washington.

ICF KH, 1995, AP 6, Corrective Action Management, ICF Kaiser Hanford Company, Richland, Washington.

WHC-CM-1-4, Corrective Action Management Manual, Westinghouse Hanford Company, Richland, Washington.

WHC, 1996, Hanford Action Tracking System(HATS) Council Charter, Westinghouse Hanford Company, Richland, Washington. 


\section{THG PAGE INTENTIONALLY LFT BLANK.}


WHC-EP-0907 REV.0

APPENDIX A

\section{DEFINITIONS FOR: COMMITMENT TRACKING}


a... TEOTENTONALYY 
WHC-EP-0907 REV.0

APPENDIX A

The Commitment Tracking glossary standard, from the sitewide Data Standards Library, serves as a baseline of standard business names and definitions used in the development or modification of a commitment, action, activity, or issues tracking system. The names in parentheses are the HATS user names that correspond to the standard business names.

\section{DEFINITIONS FOR: COMMITMENT TRACKING}

USER NAMES: Commitment Tracking, Action Tracking, Activity Management, Issues Management

SCOPE: Hanford Site

DEFINITION: List of standard names and definitions for tracking commitments and action items.

1 - Commitment Identifier - Uniquely identifies the commitment, usually a number or a code.

(Originating Document System Identification Number)

(Condition System Identification Number)

(Action System Identification Number)

2 - Commitment Originator Name - Person responsible for specifying the commitment source. May not be the originator of the commitment.

(Role Originator Name)

3 - Commitment Originator Organization Identifier - Organization assigning the action.

(Initiating Document Originating Organization)

4 - Commitment Originating Document Identifier - Number or Name of the source document specifying the commitment. Examples include audit, occurrence report, and readiness review.

(Originating Document Number) 


\section{WHC-EP-0907 REV.0}

APPENDIX A

5 - Commitment Origination Date - Date commitment originated as specified by the document or other source.

(Initiated Date)

6 - Commitment Due Date - Expected or required date for completion of the commitment.

(Condition Level--Original Planned Completion Date)

(Action Level------Original Action Due Date)

7 - Commitment Adjusted Due Date - Current adjusted due date.

(Condition Level--Current Planned Completion Date)

(Action Level------Current Action Due Date)

8 - Deliverable Receiver Name - The person accepting proof of completion on the commitment.

(Condition Closure Authority)

9 - Commitment Receiver Organization Identifier - The organization accepting proof of completion on the commitment.

(Condition Closure Authority Organization Code)

10 - Commitment Actionee Name - Person responsible for the action.

(Actionee)

11 - Commitment Actionee Organization Identifier - Organization responsible for the action. (Actionee Organization Code)

12 - Commitment Received Date - Date commitment received by the actionee organization. (Condition In Progress Date)

13 - Commitment Assigned Date - Date commitment is assigned to actionee. (Action in Progress Date) 


\section{WHC-EP-0907 REV.0}

\section{APPENDIX A}

14 - Commitment Title - Descriptive title for the commitment (Action Title)

15 - Commitment Description - Textual description defining the commitment or what action is to be done.

(Condition Abstract)

16 - Commitment Deliverable Description - Textual description of what the originator expects to be delivered to complete the action or commitment.

(Action Abstract)

17 - Commitment Completion Date - Date required action is completed (Action Completed Date)

18 - Commitment Closed Date - Date the completed action is approved by a person of authority.

(Action Closed Date)

19 - Commitment Response Description - Textual description of what was done, the action performed.

(Action History Text Field)

20 - Commitment Status Text - Description of the action's current status.

(Initiating/Condition/Action Status)

21 - Reference Document Identifier - Document Name or Number related to the action or commitment (e.g., audit, surveillance report.).

(Condition Class) 


\section{WHC-EP-0907 REV.0}

APPENDIX A

22 - Commitment Priority Code - A code that is an indication of the relative importance of the action or commitment. The Priority Planning Grid (PPG) may be used as a guide where appropriate.

(PPG Value)

23 - Commitment Action Type Code - A code that categorizes the source of the commitment (e.g., Tiger Team, Witzig).

(Condition Alias/Condition Xref)

24 - Commitment Level Code - A code that provides a tracking mechanism as actions are sent to lower levels by identifying the hierarchical level of management interested in the action.

(Condition Closure Organization Code)

SOURCE: Contracts Data Management and Integration is the focal point for these definitions.

COMMENTS: This set of terms serves as a baseline in the development or modification of a commitment, action, activity, or issues tracking system.

STATUS/DATE: Approved June 16, 1995 
WHC-EP-0907 REV. 0

APPENDIX B

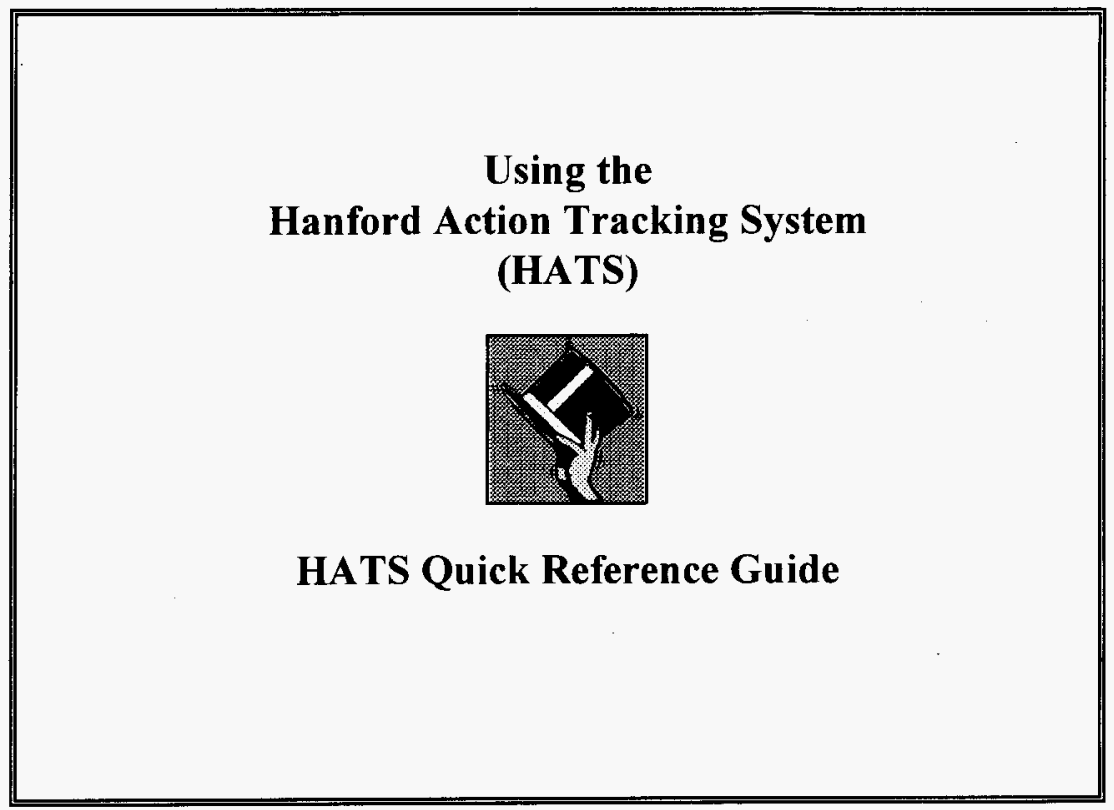

B-i 

WHC-EP-0907 REV. 0

TABLE OF CONTENTS

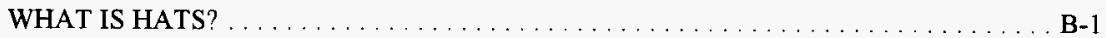

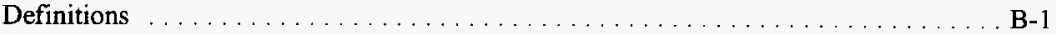

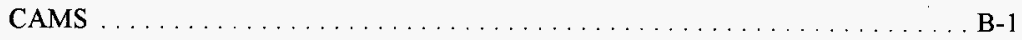

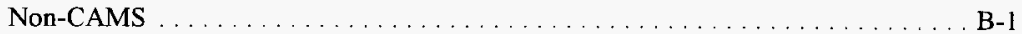

REQUIRED HARDWARE AND SOFTWARE $\ldots \ldots \ldots \ldots \ldots \ldots \ldots$ B-1

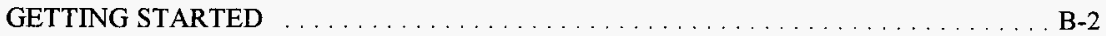

Access Approval . . . . . . . . . . . . . . . . . . . . . . . . . .

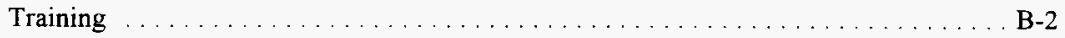

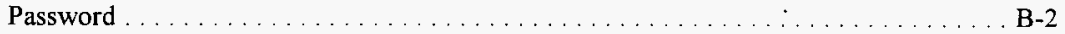

Help Desk . . . . . . . . . . . . . . . . . . . . . . . . . . B-2

WHO TO CALL . . . . . . . . . . . . . . . . . . . . . . . .

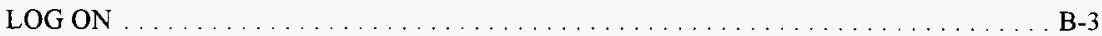

Hot Keys ... . . . . . . . . . . . . . . . . . . . . . . . . . .

Spell Check . . . . . . . . . . . . . . . . . . . . . . . . . . . . B-3

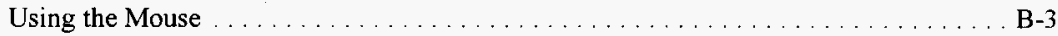

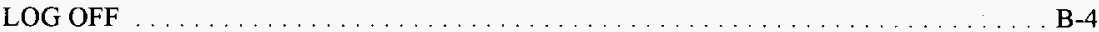

REPORTS . . . . . . . . . . . . . . . . . . . . . . . . . .

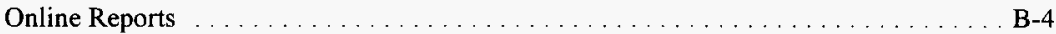

Count Reports . . . . . . . . . . . . . . . . . . . . . . . . . B-4

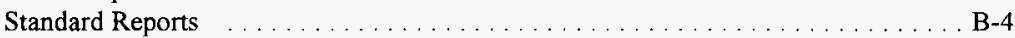

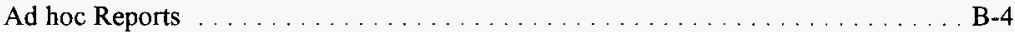

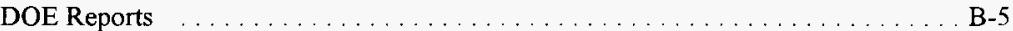

Miscellaneous Reports . . . . . . . . . . . . . . . . . . . . . B-5

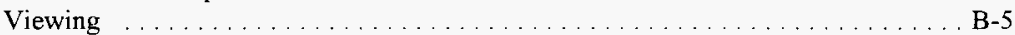

Running Reports (Samples) . . . . . . . . . . . . . . . . . . . . .

Run a Count Report . . . . . . . . . . . . . . . . . . . . . . . B-5

Run a Standard Summary Report $\ldots \ldots \ldots \ldots \ldots \ldots \ldots \ldots \ldots \ldots \ldots \ldots \ldots$

Run a Standard Detail Report . . . . . . . . . . . . . . . . . . . . B-6

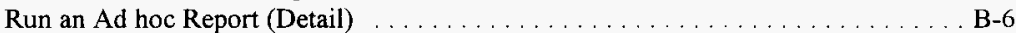

Run an Ad hoc Report (Summary) . . . . . . . . . . . . . . . . . B-6

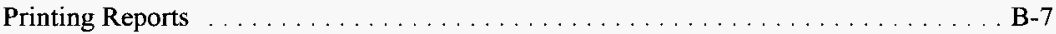

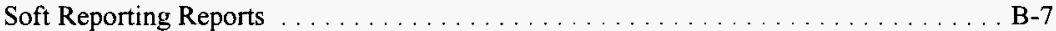

Users with or without Soft Reporting HATS Password $\ldots \ldots \ldots \ldots \ldots \ldots$ B-7 
WHC-EP-0907 REV. 0

Users with Soft Reporting HATS Password $\ldots \ldots \ldots \ldots \ldots \ldots \ldots \ldots \ldots$ B-8

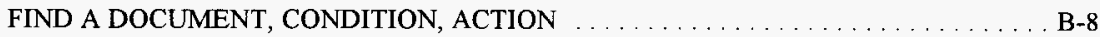

ENTER A DOCUMENT . . . . . . . . . . . . . . . . . . . . . . . . . B-9

Hats Required Fields Entry . . . . . . . . . . . . . . . . . . . . B-10

How to Input an Initiating Document $\ldots \ldots \ldots \ldots \ldots \ldots \ldots \ldots \ldots \ldots \ldots \ldots \ldots \ldots$

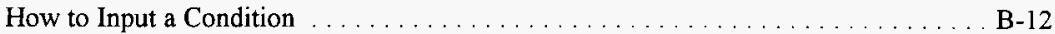

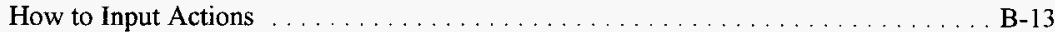

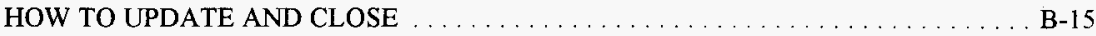

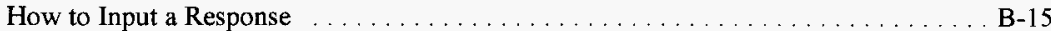

How to Approve a Condition Response . . . . . . . . . . . . . . . . . . B-15

How to Approve an Initiating Document Response . . . . . . . . . . . . . . B-15

How to Modify a Role Name . . . . . . . . . . . . . . . . . . . . . . . . B-16

How to Change a Planned Completion Date $\ldots \ldots \ldots \ldots \ldots \ldots \ldots \ldots \ldots \ldots$. $\ldots \ldots \ldots$

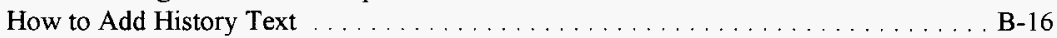

How to Complete an Action . . . . . . . . . . . . . . . . . . . . . . . B-16

How to Close a Condition . . . . . . . . . . . . . . . . . . . . . . B-16

How to Close an Initiating Document . . . . . . . . . . . . . . . . . B-16

ENTRY FOR SATISFACTORY SURVEILLANCES $\ldots \ldots \ldots \ldots \ldots \ldots \ldots$ B-17

ENTRY FOR NON-CAMS ADMINISTRATIVE ACTIVITIES $\ldots \ldots \ldots \ldots \ldots$ B-18 


\section{WHC-EP-0907 REV. 0}

\section{WHAT IS HATS?}

The Hanford Action Tracking System (HATS) is the Sitewide database used to enter, track, manage, and report the status of internally and externally identified conditions and deficiencies and their associated actions. This quick reference guide applies to Corrective Action Management System (CAMS) data and non-CAMS data.

\section{Definitions}

\section{CAMS}

The system utilized to ensure adverse conditions are identified, tracked, and resolved. It uses a graded approach to performing evaluations and analysis, correcting conditions and root causes, and verifying correction action effectiveness for formally reported conditions

\section{Non-CAMS}

A term used for items that are tracked in the HATS database but do not meet the formal definition of CAMS. For example, nonconformance reports are not CAMS items and are tracked in the HATS database.

Access to the HATS is available to users who are employed by a U.S. Department of Energy, Richland Operations Office (RL) primary contractor and have been approved by Contracts, Data Management and Integration (CDM) as having a "need to know."

HATS is managed by CDM. HATS resides on a Sun SPARCserver ${ }^{1}$ and is operated by BCS Richland, Inc. Access to HATS is through a personal computer (PC) workstation at the user's location with communication to the HATS file server through the Hanford Local Area Network (HLAN).

\section{REQUIRED HARDWARE AND SOFTWARE}

To use the HATS, you must have the following computer hardware and software:

- Minimum 386 PC

- 10 Mbyte hard drive storage

- WordPerfect for Windows, Version 6.0 $\mathrm{A}^{2}$

- Microsoft Windows, Version $3.1^{3}$ or later

- MS/DOS 6.0

- End system operating environment (ESOE) and transmission control protocol/Internet protocol (TCP/IP) network connections

- Hewlett Packard LaserJet $\mathrm{II}^{5}$ or later

- 8 Mbyte memory.

\footnotetext{
${ }^{1}$ Sun SPARCserver is a trademark of Sun Microsystems, Inc

${ }^{2}$ WordPerfect is a trademark of the WordPerfect Corporation.

${ }^{3}$ Windows is a trademark of the Microsoft Corporation.

${ }^{4} \mathrm{MS} / \mathrm{DOS}$ is a trademark of the Microsoft Corporation.

${ }^{5}$ Hewlett Packard is a trademark of the Hewlett Packard Corporation.
} 
WHC-EP-0907 REV. 0

\section{GETTING STARTED}

The HATS Quick Reference Guide is designed to help you find information quickly. Complete explanations are located in the HATS User Guide (located in the HATS Help).

Access Approval - To obtain access to HATS, the requester completes Site form A-6001-513, "Hanford Action Tracking System (HATS) Access Checklist"; obtains the manager's signature; and forwards the checklist to CDM by plant mail at B3-56.

Training - After access approval, the HATS trainer will contact the requester to schedule training. CDM provides one-on-one and group training for customers on the HATS database.

Password - A password will be issued at the time of training. Users are responsible for protecting their passwords and are prohibited from disclosing their passwords to other persons.

Help Desk - For help, general questions, access problems, understanding an error message, and troubleshooting assistance, contact the HATS help desk on 376-7273, or via electronic mail at address "^Hanford Action Track Sys-HATS." In an emergency (e.g., loss of data), contact CDM on 376-2191.

\section{WHO TO CALL}

Administered by Contracts, Data Management and Integration, B3-56, 1100 Jadwin, Room 354.

\section{HATS}

Project Lead:

Terri M. Lutter

376-2991

System Data Administrator:

Kaye A. Ray

$376-2191$

Help Desk, Training, .

and Users' Point of Contact:

Rosemary Keasling

$376-7273$

\section{SHARE}

SHARE Database:

Kelly A. Layfield

$376-6785$

Point of Contact:

Bob B. Balthazor

$376-4910$

WHC-CM-1-4, Corrective Action Management Manual

WHC/Tiger Team \&

Performance Assessment Team conditions 
' doo ol $\supset$ l.1

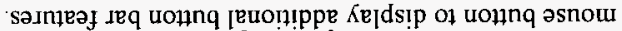

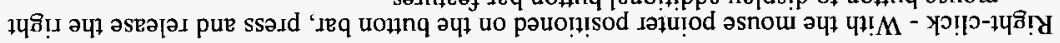

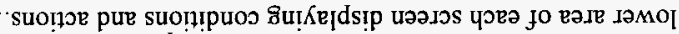

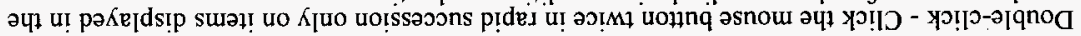

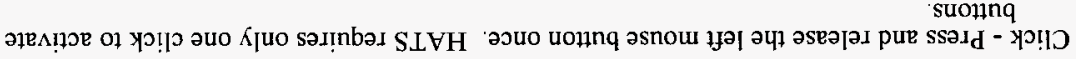
:asnouI

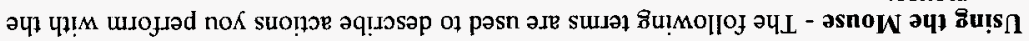

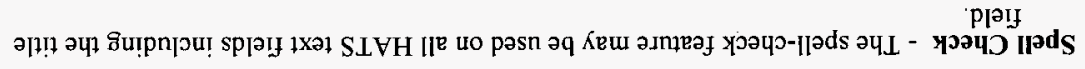
'əsnow

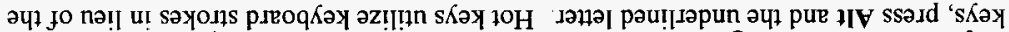

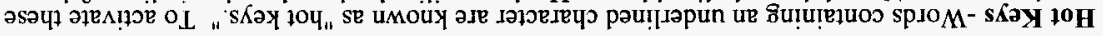

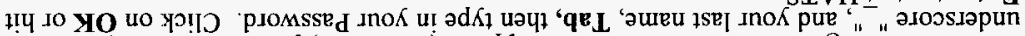

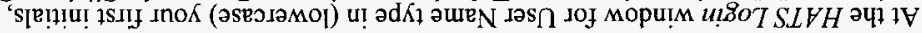

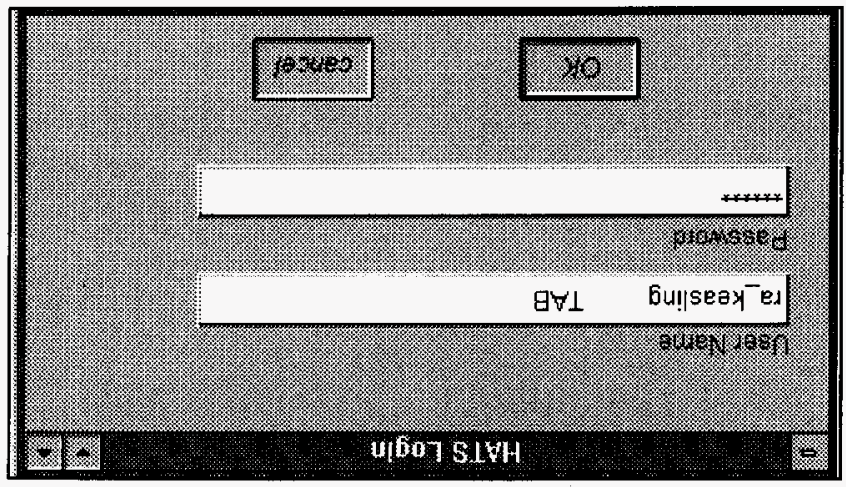

морuıм 4 iso7

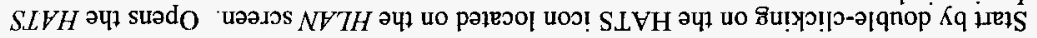

\section{NO פo'T}


WHC-EP-0907 REV. 0

Paste text - With the mouse, place cursor at the location the text is to be entered. Press Ctrl V. Copied text will appear. 
WHC-EP-0907 REV. 0

\section{LOG OFF}

There are three ways to exit HATS. You may click on File in the HATS menu bar, then click on Exit; double-click in the far-most upper left-hand corner of HATS; or click on the "blue door" icon in the button bar. If you have any initiating document, condition, or action screens displayed, they will automatically be closed upon exiting regardless if you have saved or not.

\section{REPORTS}

There are two methods to obtain the HATS reports: ONLINE REPORTS provide access to all "open" and "closed" records in the HATS database, and SOFT REPORTING REPORTS provide access to only "open" records. Both methods display reports in three formats:

Count - the total number of open conditions and actions by organization code

Summary - a one-line report of conditions and their related actions providing the Owner organization, Condition and Action Title, and their current status

Detail - a more informative report providing initiating document information; roles, dates, and the condition/action description (abstract) text and comment (history) text.

\section{ONLINE REPORTS}

Selecting online reports will retrieve all open and closed conditions and their related actions. To access these reports, click on the Reports option on the HATS menu bar. Each menu option provides a standard format that users may populate. Displayed are: Counts, Standard, Ad hoc, DOE, and Misc.

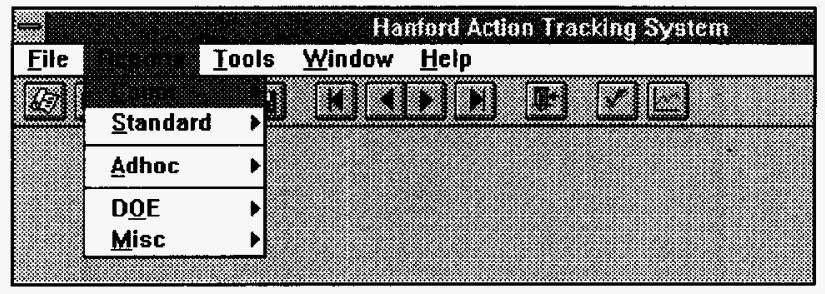

Count Reports - Provides the total number of open conditions and actions by Levels 1-4 Responsible Organizations.

Standard Reports - Retrieves all open conditions and actions by Responsible and Originating Organization in summary and detail report formats.

Ad hoc Reports - Retrieves all open and closed conditions and actions in summary and detail report formats, and are dependent upon the user's selection of data fields to be queried. Each field has a picklist which contains all of the values for that field type. Name and organization field picklists are downloaded from PeopleCORE on a weekly 


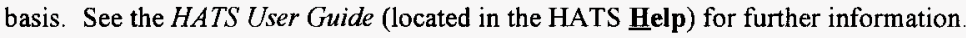

\section{REPORTS (Continued)}

Department of Energy (DOE) Reports - Contains reports which were created at the request of the $R L$ representative.

Miscellaneous (Misc) Reports - Provides administrative reports by initiating document, condition, and action listing the record modified, the database administrator (DBA) that performed the modification, and the date of the modification

Selecting organization codes for reports are as follows (the "\%" will pad the organization code with the required alphanumeric characters):

\begin{tabular}{c} 
Organization Level \\
\hline Level 1 \\
Level 2 \\
Level 3 \\
Level 4
\end{tabular}

\begin{tabular}{c} 
Organization Code \\
\hline $3 \%$ \\
$38 \%$ \\
$384 \%$ \\
$3842 \%$
\end{tabular}

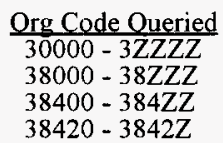

Org Code Queried $38000-38 Z Z Z$

$38400-384 Z Z$

$38420-3842 Z$

Viewing - To view reports, use the mouse to click on the arrows located along the right-hand side and along the bottom of the screen. To view the next page, select the Page Down button on your keyboard.

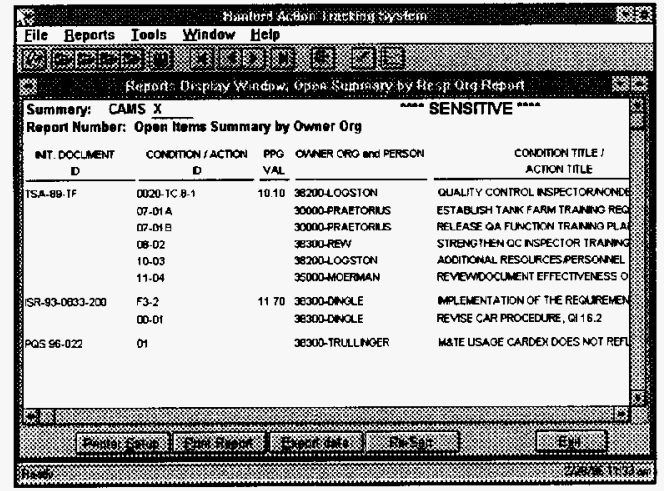

RUNNING REPORTS (SAMPLES)

\section{Run a Count Report}


Click on Reports. Click on Count. Displayed are count reports by Level 1-4 responsible organizations. Select the report for Level 2 by Resp. Org.

A Standard Report Selection Window: Level 2 Count Report window will appear. Type in $\mathbf{3 8 \%}$ in the Responsible Org: field (to run a report for all of organization 38000). Click on the Run Report button. This will retrieve a count of all open records assigned to Organization Code 38000. 


\section{THE PAOE ATENTIUNALLY LEFT BLANK.}


WHC-EP-0907 REV. 0

REPORTS (Continued)

\section{Run a Standard Summary Report}

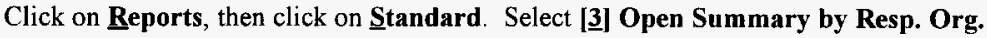
A Standard Report Selection Window: Open Summary by Resp Org Report window will appear. Enter the desired Responsible Organization code (you may use the wildcard \%). Click on the Run Report button.

A Reports Display Window: Open Summary by Resp Org window is displayed.

The report is displayed in order by responsible organization code, then by initiating document number.

\section{Run a Standard Detail Report}

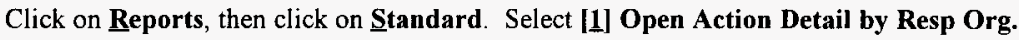

A Standard Report Selection Window will appear. Type 38\% in the Responsible Org field (to run a report for organization 38000). Select an option to run the report with or without the abstract text. Click on $\underline{\text { Run Report. }}$

The Reports Display Window: Open Action Detail by Resp Org Report window will appear.

\section{Run an Ad hoc Report (Detail)}

Click on $\underline{\text { Reports, }}$ then click on Ad hoc. Select Detail - $\underline{\text { Actions report. }}$

A Report Selection Window: Action Detail Report window will appear. Click on the Condition Owner Org field and type in $\mathbf{3 8 \%}$ (to run a report for all of organization 38000). Click on Run Report.

An Ad Hoc Query Results Window screen will appear providing the total number of records found. Click on Display.

A Reports Display Window: Action Detail Report screen will appear.

\section{Run an Ad hoc Report (Summary)}

Click on Reports, then click on Ad hoc. Select Summary.

A Report Selection Window: Summary Report screen will appear. Click on the Responsible Org field and type in $\mathbf{3 8 \%}$ (to run a report for all of organization 38000 ). Click on Run Report.

An Ad Hoc Query Results Window screen will appear providing the total number of records found. Click on Display.

A Reports Display Window: Summary Report screen will appear.

FOR MORE DETAILED INSTRUCTIONS ON AD HOC REPORTS, SEE THE HATS USER 
WHC-EP-0907 REV. 0

GUIDE (located in the HATS Help). 


\section{WHC-EP-0907 REV. 0}

\section{REPORTS (Continued)}

\section{PRINTING REPORTS}

Click on the Print Report button located at the bottom of the report screen.

A Report Print Options screen is displayed. Select the number of copies, Page Range, etc. The majority of the HATS reports are displayed and printed in landscape compressed. To verify the printer is set up to print landscape compressed, perform the following:

Click on the Printer... button. Select the correct printer. (For the purpose of this guide, HP LaserJet III on LPTI was selected.)

Click on the Setup button. The HP LaserJet III screen will appear. Under Orientation, change the Portrait option to the Landscape option.

Click on the OK button. Also click on the OK button on the Printer Setup screen.

At the Report Print Options screen, click on the $\mathbf{O K}$ button. The Print: HP Laser.Jet III on LPTI: window will appear. Report will begin printing the selected pages.

\section{SOFT REPORTING REPORTS}

Numerous reports are available from the HATS directory in Soft Reporting. The HATS Soft Reports are updated on a nightly basis.

To obtain access to the password-protected HATS reports on Soft Reporting, the requester completes Site Form \#A-6001-512, "Hanford Action Tracking System (HATS) Soft Reporting Access Checklist"; obtains the manager's signature; and forwards the checklist to to CDM by plant mail at B3-56. Soft Reporting will notify the requester of their password

\section{Users with or without Soft Reporting HATS Password}

The following HATS reports do not require a password. To access them, enter Soft Reporting and highlight HATS: Hanford Action Tracking System DIR and press Enter. To access HATS administrative reports, highlight HATS Administrative Information Reports, and press Enter. Press F2 and you will see the following list of HATS administrative reports:

Points of contact for HATS are listed on Soft Reporting under "Hanford Action Tracking System," "HATS Administrative Information Reports," "Information Guide."

\footnotetext{
- System Bulletin

- DOE Direct Cause and Root Cause Codes

- HATS DBA by Org Code

- Information Guide
} 
WHC-EP-0907 REV. 0

\section{REPORTS (Continued)}

\section{Users with Soft Reporting HATS Password}

The following HATS reports require a password. To access them, highlight one of the following report groups and press Enter:

H000 HATS Administrative Reports

H01A HATS Reports by Responsible/Actionee Organization

H01B HATS Reports by Level 1, 2, 3, 4 Resp/Act Organization

HOID HATS Reports by Initiating Document $\mathrm{D}$ and Class

HOIF HATS Reports by Facility

H01K HATS Reports by Originating Organization

H01P HATS Reports by Priority Range

H01V HATS Reports by Verification/Closure Organization

H02N HATS Reports for Non-CAMS/CAMS

HSTY HATS Reports for Tiger Team Date

A list of reports will appear. Highlight the report you want and press Enter.

\section{FIND A DOCUMENT, CONDITION, ACTION}

You may find a document by clicking on one of the yellow "folder" buttons in the button bar, or click on File, Open.

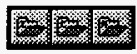

A "Find" document screen will appear.

You may use the search operators "LIKE" and "\%" key to "find" a document if the exact number is unknown:

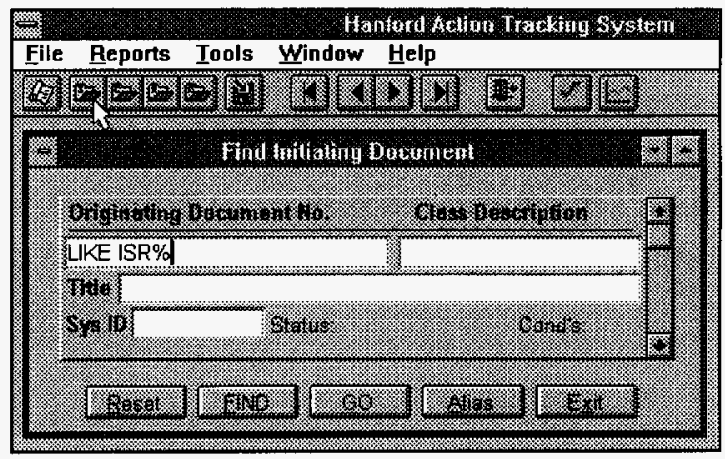
LIKE \%ISR \% =
LIKE \%ISR
$=$
Will retrieve any record containing "ISR" in the document number
LIKE ISR\% Will retrieve any reco
number are "ISR"
$=$ Will retrieve any record where the first characters in the document start with "ISR."

If more than one record is retrieved, a scroll bar will appear on the right-hand side. Scroll to find the needed document, highlight the document number to select this record, click on $\mathbf{G}$ o. This will retrieve your document. 
WHC-EP-0907 REV . 0

\section{FIND A DOCUMENT, CONDITION, ACTION (Continued)}

To retrieve a specific document, type in an initiating document number exactly as it was entered in the HATS.

\section{For example, type in: ISR-95-001-FFTFQA.}

Click on Find, click on $\mathbf{G} \mathbf{0}$. This will retrieve your document.

DO NOT click on Find All. It will retrieve ALL records in the HATS database.

To locate another initiating document, return to the Find Initiating Document screen, click on the Reset button, and enter the desired document number to be retrieved. Follow directions above.

\section{ENTER A DOCUMENT}

Click on the Create icon in the top-left side of the button bar, or click on File and select Create InitDoc. An Initiating Document: Insert Mode screen appears.

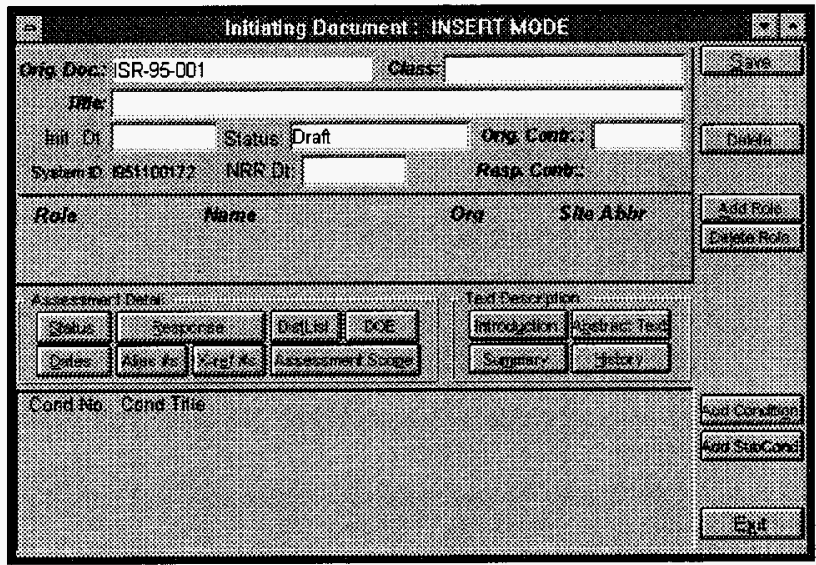

Enter information into the required fields listed below. Data must be entered into these fields before the record can be "saved" in the database. To navigate from field to field, use the Tab key. 


\section{HATS REQUIRED FIELDS ENTRY}

Enter Initiating Document:

Originating Document \#

Class

Title

Originating Contractor

Originator

Responsible

Abstract Text, Save

Save - upper right corner of screen.

\section{* Add Condition(s) button \\ Condition Number \\ Type \\ Title \\ View \\ Responsible Contractor \\ Owner (Responsible, can be overridden) \\ Abstract Text - $\underline{\text { Save }}$}

Save - upper right corner of screen.

* Repeat the "Add Condition" step as necessary.

After all of the Conditions have been entered and are ready to go from DRAFT status to RESPONSE DUE, return to the Initiating Document screen. At the Dates button, enter the Initiated Date (the

Response Due Date automatically defaults to 30 days from the Initiated Date).
When you receive the response, retrieve the Condition Document screen.

\author{
** Add Action(s) button \\ Action Number \\ Title \\ Owner \\ Abstract Text - Save
}

Save - upper right corner of screen.

Click on the Dates button, enter Action Due Date. The date of the last action due to be completed will automatically populate the Condition Plan Completion Date in the Condition Dates area.

** Repeat the "Add Action" as necessary.

Return to the condition. At the Response button, enter the Submitted date - $\underline{\text { Save, }}$ Exit

After all actions have been entered on all of the conditions, and the Submitted date has been entered on all of the conditions, return to the Initiating Document screen. At the Response button, enter the Submitted date Save, Exit.

\section{HOW TO INPUT AN INITIATING DOCUMENT}

When you start HATS, the program displays a blank window. To enter a new initiating document, follow these steps:

1. Open the File menu and choose the Create InitDoc option, or click on the Create Initiating Document button from the HATS button bar.

2. Begin typing in the HATS Initiating Document: INSERT MODE screen.

\section{REQUIREMENTS FOR INITIATING DOCUMENT INITIAL ENTRY}

\section{Enter Initiating Document Number}

This is an alphanumeric free-form text field. The number should be a combination of information including: finding process (e.g., surveillance, audit, self-assessment), the year originated, log number, and facility or project. For example: ISR-95-005-TPLANT. Enter the number into the Orig.Doc. field. Tab to the Class field 
WHC-EP-0907 REV. 0

\section{Enter Class}

This is a picklist. Select an initiating document Class. This is the class or type of initiating document. Tab to the Title field.

\section{ENTER A DOCUMENT (Continued)}

\section{Enter Title}

Enter the initiating document Title field. The title should contain logical information describing the contents of the document. For example: "COLD WEATHER

PROTECTION PROGRAM - T PLANT WATER UTLITIES." (A title such as

"CONDUCT OF OPERATIONS" does not provide enough information.) This is a 70character alphanumeric field. Tab to the Orig. Contr. field.

\section{Select Originating Contractor}

The Orig. Contr. field is a picklist. Select the contractor or government agency that originated the initiating document. Tab to the Resp. Contr. field.

\section{Assign an Initiating Document Originator Role/Name/Org}

a) Click on the Role field. Select Originator. Tab to the Name field.

b) Enter the last name, first name, and middle initial of the Originator (or you may enter at least two letters of the last name, click on the down arrow, highlight and click on the Originator's name). Tab to the Org field.

c) An organization code will appear in the Org field. Tab through this field if this is the correct organization code. If a different organization code is desired, enter the first two characters of the organization code, click on the down arrow, and highlight the correct organization.

\section{Assign an Initiating Document Responsible Role/Name/Org}

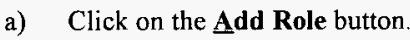

b) Click on the Role field. Select Responsible. Tab to the Name field.

c) Enter the last name, first name, and middle initial of the Responsible person (or you may enter at least two letters of the last name, click on the down arrow, and highlight and click on the Responsible person's name). Tab to the Org field.

d) An organization code will appear in the Org field. Tab through this field if this is the correct organization code. If a different organization code is desired, enter the first two characters of the organization code, click on the down arrow, and highlight the correct organization code. Tab through this field to have the organization code accepted.

NOTE: If the item is RL-generated, and the Responsible person is unknown, enter the assessed contractor point of contact (e.g., Britton, Mary Kay for ICF KH/WHC).

\section{Enter Abstract Text}

Click the cursor on the Abstract Text button or press the Alt/B keys simultaneously.

The Abstract Text window will appear. Enter a summarized description of the initiating document providing logical information. This is a 255 -character alphanumeric text field. Click on Save or press the Alt/S keys simultaneously. 
WHC-EP-0907 REV 0

An Abstract Save window will appear. Click on $\mathrm{OK}$ or press Enter.

NOTE: If the description is greater than 255 characters, enter the text in the word processing buttons (Introduction, Summary) located in the Text Description area. 


\section{ENTER A DOCUMENT (Continued)}

\section{Save Initiating Document}

Click on the Save button in the upper right-hand corner of the screen to save this initiating document information

An Add Initiating Document window will appear. Select No.

CAMS ITEMS: The initiating document is in DRAFT status. To go from DRAFT status to RESPONSE DUE, you must first add the Condition(s), and then return to the Initiating Document and enter the Initiated Date.

NOTE: For Non-CAMS items, the status will go from DRAFT to ACTIVE when you enter the Initiated Date in the Initiating Document.

\section{HOW TO INPUT A CONDITION}

After you have entered an initiating document, you may now input a condition. To enter a new condition, follow these steps:

1. Click on the Add Condition button from the Initiating Document screen.

2. Begin typing in the HATS Condition Document: INSERT MODE screen.

\section{REQUIREMENTS FOR CONDITION INITLAL ENTRY}

\section{Enter Condition Number}

The Initiating Document Number will appear in the first section of the Condition No. field. The cursor will appear in the second section of the Condition No. field. Enter the identification number of the condition in the Condition No. field. Consider the type of condition (e.g., $\mathbf{F}$ for finding, $\mathbf{O}$ for observation, $\mathbf{C}$ for concern) and provide a numerical value in sequence (e.g., 01 should be used when there are between 10 and 99 conditions; 001 should be used when there are more than 99 conditions). This is a six-character alphanumeric free-form text field.

\section{Select a Condition Type}

This is a picklist. Select a condition Type. This is the type of the condition (i.e., condition, non-CAMS, self-identified [SI], noteworthy practice [NP], etc.) Tab to the Title field.

\section{Enter a Condition Title}

Enter the Condition Title. The title should contain logical information describing the contents of the condition. For example: "THERE IS NO MECHANISM IN PLACE TO ENSURE THAT REPORTS ARE PROVIDED." (A title such as "PROCEDURE NOT IN COMPLIANCE" does not provide enough information.) This is a 70-character alphanumeric field. Tab to the View field.

\section{Select a Condition View}

Select the Condition View. The view tags the condition as part of a logical group of conditions. At a minimum, users will have read-only privileges of all unrestricted views Views may be restricted. Restricted views may be added to the view list and will be available only to approved users. Tab to the Resp. Contr. field.

\section{Select Responsible Contractor}




\section{WHC-EP-0907 REV. 0}

The Resp. Contr. field is a picklist. Select the code used to identify the responsible contractor. Tab to the Role field. 
WHC-EP-0907 REV. 0

\section{ENTER A DOCUMENT (Continued)}

\section{Assign a Condition Owner}

Assign a condition owner in the Role/Name/Org fields. The condition owner will automatically default to the initiating document responsible person. This may be overridden.

a) Click on the Role field. Select Owner. Tab to the Name field.

b) Enter the last name, first name, and middle initial of the Owner (or you may enter at least two letters of the last name, click on the down arrow, and highlight and click on the Owner's name). Tab to the Org field.

c) An organization code will appear in the Org field. Tab through this field if this is the correct organization code. If a different organization code is desired, enter the first two characters of the organization code, click on the down arrow, and highlight the correct organization code. Tab to the next field or move the cursor to the Role field to add another role.

\section{Enter Abstract Text}

Click the cursor on the Abstract Text button or press the Alt/B keys simultaneously.

The Abstract Text window will appear. Enter a summarized description of the condition providing logical information. This is a 255 -character alphanumeric text field. Click on Save or press the Alt/S keys simultaneously.

The Abstract Save window will appear. Click on $\mathbf{O K}$ or press Enter.

NOTE: DO NOT enter the Condition Planned Completion Date (PCD). This date will automatically be populated by the action(s). If there are no actions, e.g., for non-CAMS, you may enter a PCD.

\section{Save Condition}

Click on the Save button to save this condition document information. The Add Condition window will appear. If you select $\underline{Y} e$, a new condition window will appear. You can now enter a new condition. If you select No, the current condition screen will remain open. You can now enter additional condition information.

CAMS ITEMS: The condition is in DRAFT status. To go from DRAFT status to RESPONSE DUE, you must return to the Initiating Document and enter the Initiated Date, found under the Dates button.

NOTE: For Non-CAMS items, the status will go from DRAFT to ACTIVE when you enter the Initiated Date in the Initiating Document.

\section{HOW TO INPUT ACTIONS}

After the initiating document and conditions have a status of RESPONSE DUE, actions and response information may be entered. To enter actions, follow these steps:

1. Click on the Add Action button located on the Condition screen.

2. Begin typing in the HATS Action: INSERT MODE screen. 
WHC-EP-0907 REV. 0

B-19 
WHC-EP-0907 REV. 0

ENTER A DOCUMENT (Continued)

\section{REQUIREMENTS FOR ACTION INITIAL ENTRY}

\section{Enter Action Number}

The Initiating Document Number and the Condition No. will appear in the first two sections of the Action No. field. The cursor will appear in the Action No. field. Enter the identification number of the action into the Action No. field. Provide numerical values in sequence (e.g., 01 should be used when there are between 10 and 99 actions; 001 should be used when there are more than 99 actions). This is a 7-character alphanumeric free-form text field.

\section{Enter the Action Title}

Enter the title of the action. It should contain logical information describing the contents of the action. For example: "INSTALL SIGNS AT STAIRWAYS." (A title such as "REVISE PROCEDURE" does not provide enough information.) This is a 70-character alphanumeric free-form text field. Tab to the Role field.

\section{Assign an Action Owner}

Assign an action owner in the Role/Name/Org fields.

a) Click on the Role field. Select Owner. Tab to the Name field.

b) Enter the last name, first name, and middle initial of the Owner (or you may enter at least two letters of the last name, click on the down arrow, and highlight and click on the originator's name). Tab to the Org field

c) An organization code will appear in the Org field. Tab if this is the correct organization code. If a different organization code is desired, enter the first two characters of the organization code, click on the down arrow, and highlight the correct organization code. Tab to the next field or move the cursor to the Role field.

\section{Enter Abstract Text}

Click the cursor on the Abstract Text button or press the Alt/B keys simultaneously.

The Abstract Text window will appear. Enter a summarized description of the action providing logical information. This is a 255-character alphanumeric text field. Click on

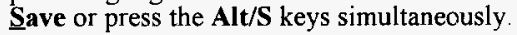

The Abstract Save window will appear. Click on OK or press Enter.

Save Action

Click on the Save button in the upper right-hand corner of the screen to save this action document information. The Add Action window will appear. If you select Yes, a new action window will appear. You can now enter a new action. If you select $\underline{\mathbf{N}} \mathbf{0}$, the current action screen will remain open. You can now enter additional action information.

NOTE: This action is in DRAFT status. To go from DRAFT to IN PROGRESS status, you must do the following

For each action, enter the Action Due Date in the Action Due Date field found in the Action screen under the Dates button. 
WHC-EP-0907 REV. 0

\section{HOW TO UPDATE AND CLOSE}

\section{HOW TO INPUT A RESPONSE}

Input Condition Response Information

After the initiating document and conditions have a status of RESPONSE DUE and all actions for the condition have a status of IN PROGRESS, the response information may be entered. To enter condition responses, follow these steps:

1. Click on the Response button located on the Condition screen.

2. Enter the narrative text responding to the condition in the Discussion Text field.

3. Enter the response submitted date in the Submitted field.

4. Click on the Save button or press the Alt/S keys simultaneously to save this information.

5. Click on the Exit button or press the Alt/X keys simultaneously to exit this window.

NOTE: The status of the condition will charge from RESPONSE DUE to IN PROGRESS. The status of the initiating document will remain in RESPONSE DUE status until all response information is entered on the initiating document.

\section{Input Initiating Document Response Information}

After all of the conditions for an initiating document have a status of IN PROGRESS, the initiating document response information may be entered. To enter an initiating document response, follow these steps:

1. Click on the Response button located on the Initiating Document screen.

2. Enter the narrative text responding to the initiating document in the Discussion Text field.

3. Enter the response submitted date in the Submitted field.

4. Click on the Save button or press the Alt/S keys simultaneously to save this information.

5. Click on the Exit button or press the Alt/X keys simultaneously to exit this window.

NOTE: The status of the initiating document will now change to OPEN.

\section{HOW TO APPROVE A CONDITION RESPONSE}

To approve a condition response, click on the Response button on the Condition Document screen. Enter the condition response approved date in the Approved field. The condition status will remain IN PROGRESS.

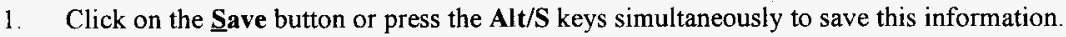

2. Click on the Exit button or press the Altt/X keys simultaneously to exit this window.

\section{HOW TO APPROVE AN INITIATING DOCUMENT RESPONSE}

To approve an initiating document response, click on the Response button on the Initiating 
Document screen. Enter the initiating document response approved date in the Approved field. The initiating document status will remaint OPEN.

\section{HOW TO UPDATE AND CLOSE (Continued)}

1. Click on the Save button or press the Alt/S keys simultaneously to save this information.

2. Click on the Exit button or press the $\mathbf{A l t} / \mathbf{X}$ keys simultaneously to exit this window.

\section{HOW TO MODIFY A ROLE NAME}

To change a Role name, highlight the name to be replaced and begin typing the last name in the name field, click on the down arrow, select the correct name from the picklist. Org Code will automatically replace also. Click on the upper right-hand Save button.

\section{HOW TO CHANGE A PLANNED COMPLETION DATE}

To change a Plan Completion Date on the Condition record(s), retrieve the Action to be extended. In the Dates button, click on the Action Due Date. Extend the date an additional 10

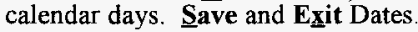

\section{HOW TO ADD HISTORY TEXT}

To add additional history or comments on a condition or action that will appear on the detail reports, click on History, click on Insert. Enter the desired information related to the document. Click on Save. This is a 250-character field. To add more information, repeat entry instructions. Click on Exit.

\section{HOW TO COMPLETE AN ACTION}

To complete an action, click on the Dates button on the Action Document screen. Enter the action completed date in the Completed field. The status of the action will now be COMPLETE.

1. Click on the $\mathbf{S} a v e$ button or press the $\mathbf{A l t} / \mathbf{S}$ keys simultaneously to save this information.

2. Click on the Exit button or press the Alt/X keys simultaneously to exit this window.

\section{HOW TO CLOSE A CONDITION}

NOTE: For CAMS items, a PPG value is required before closure.

When all of the actions for a condition have a status of COMPLETE, the condition will automatically go to PENDING VERIFICATION status.

To close a condition, click on the Dates button on the Condition Document screen. Enter the condition closed date in the Closed field. The status of the condition will now be CLOSED.

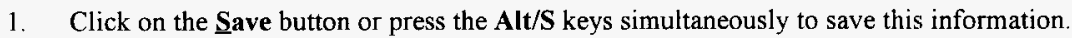

2. Click on the Exit button or press the Alt/X keys simultaneously to exit this window.

\section{HOW TO CLOSE AN INITIATING DOCUMENT}


WHC-EP-0907 REV. 0

When all of the conditions for an initiating document have a status of CLOSED, the initiating document will automatically go to CLOSED status. 
WHC-EP-0907 REV. 0

\section{ENTRY FOR SATISFACTORY SURVEILLANCES}

Enter Initiating Document:

Originating Document \#

Class $=$ Surveillance

Title

Originating Contractor

Originator

Responsible

Abstract Text $=$ Enter Title of

Surveillance, Save

Save - Upper right corner of screen.

(Introduction button, insert electronic file if available.)
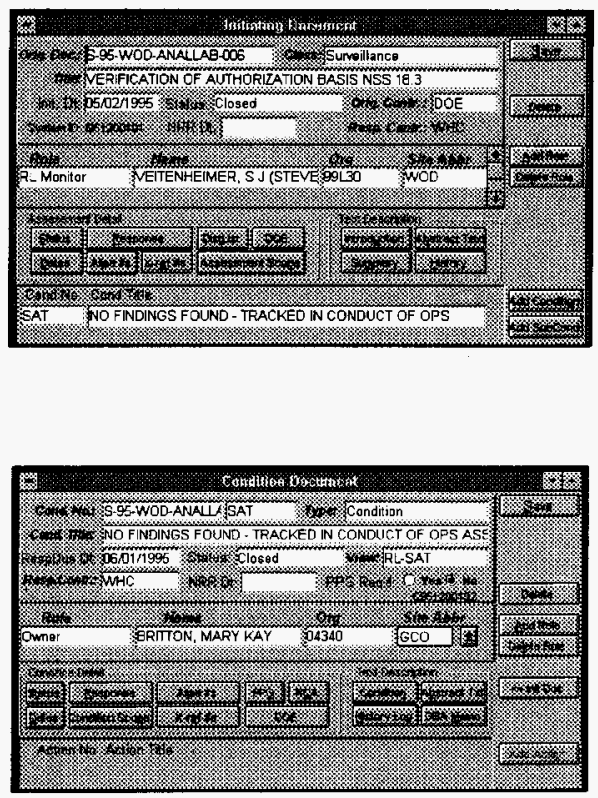

* Add Condition button Condition Number $=S A T$

Type $=$ Condition

Title = Enter "No Findings Found 'Title of Surveillance,'"

View $=R L-S A T /$ Contractor $S A T$

Responsible Contractor

Owner (Responsible, can be overridden)

Abstract Text $=$ Enter "No Findings

Found, 'Title of Surveillance,"

Save

Save - Upper right corner of screen.

To Activate: After the Condition has been entered and is ready to go from DRAFT status to ACTIVE, return to the Initiating Document screen. At the Dates button, enter the Initiated Date.

To Close: Return to the condition. At the Dates button, enter the Closed Date. This date will automatically close the Initiating Document. 
WHC-EP-0907 REV. 0

\section{HATS Entry for Non-CAMS Administrative Activities}

** Keep in mind that the only field that determines whether a record is CAMS or Non-CAMS is the "VIEW" field on the Condition Document screen and is critical for reporting purposes.

Enter Initiating Document:

Originating Document \# (i.e., CDM $A C T I V I T I E S)$

Class = Non-CAMS/Self-Assessment

Management Assessment

Title $=$ Enter the non-CAMS account title (i.e., FY96 CDM ACTIVITIES)

Originating Contractor

Originator = Enter the non-CAMS account requestor

Responsible $=$ Enter the non-CAMS account requestor

Abstract Text $=$ Enter the title or purpose of the non-CAMS account, Save

Save - Upper right corner of screen.

\section{* Add Condition button}

Condition Number (i.e., KEASLING)

Type = Non-CAMS Issue, SI Non-CAMS (self-identified non-CAMS)

Title $=$ Title of this issue (i.e., FY96 Activities for Rosemary Keasling)

View = Enter non-CAMS account acronym (i.e., CDM)

Responsible Contractor

Owner (Responsible, can be overridden)

Abstract Text $=$ Enter the title of this condition, Save

Save - Upper right corner of screen.

To Activate: After the Condition has been entered and is ready to go from DRAFT status to ACTIVE, return to the Initiating Document screen. At the Dates button, enter the Initiated Date. There will be no response due date generated unless the "CAMS" statuses have been specified for this nonCAMS account.
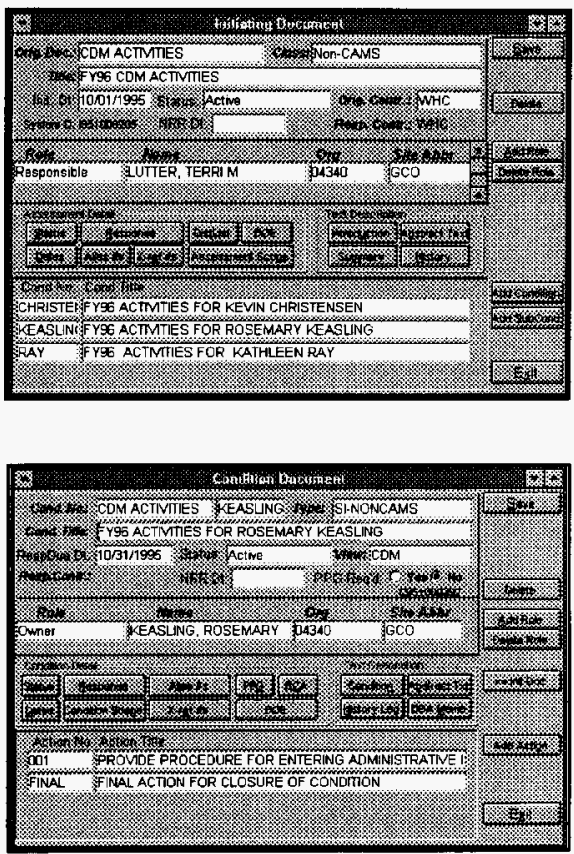


\section{WHC-EP-0907 REV. 0 \\ ENTRY FOR NON-CAMS ADMINISTRATIVE ACTIVITIES (Continued)}

A "control record" will need to be created in order for the Condition to remain "active" during it's use. This control record will remain open until all actions have been completed and the condition is ready for closure.

To establish a "control record":

* Add Action button

Action Number = Enter "Final"

Action Title = Enter "FINAL ACTION FOR CLOSURE OF CONDITION"

Owner

Abstract Text $=$ Enter Action Title, Save

Save - Upper right corner of screen

Action Completion Date $=$ Enter 10/01/96, or any future date.

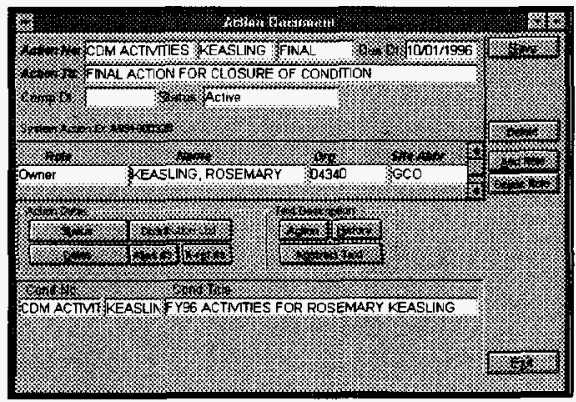

To add actions:

Return to Condition

* Add Action button

Action Number = Enter " $001 "$; this will accommodate any future actions for FY96

Action Title $=$ Enter title of action to be

Owner performed

Abstract Text $=$ Enter action description summary, Save

Save - Upper right corner of screen

Action Completion Date.

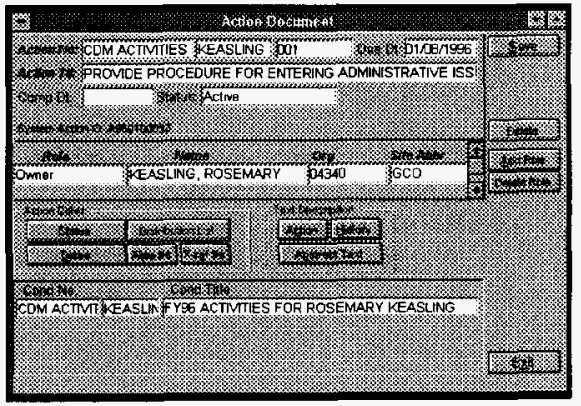

To Complete or Close an Action: Return to the action. At the Dates button, enter the Completed Date or Closed Date.

To Close a Condition: All actions, including the "Control" record, need to be completed or closed. Return to the condition. At the Dates button, enter the Closed Date. This date will automatically close the Initiating Document. 
WHC-EP-0907 REV.0

APPENDIX C

\section{Representative Listing of Implementing Procedures}

ICF Kaiser Hanford Company
AP 6
Corrective Action Management

Westinghouse Hanford Company

2-015-03

K Basins Event Investigation, Trending and Reporting

WHC-CM-1-4

Corrective Action Management

WHC-CM-5-34

Section 1.2

Solid Waste Disposal Operations Administration

Corrective Action Management

WHC-CM-5-4

Section 8.8

Laboratories Administration Corrective Action

Management

WHC-CM-5-6

Section 5.10

B Plant/WESF Transition Project Administration

Implementing Corrective Action Management

WHC-IP-0842

Volume 1 Section 2.4

TWRS Administration Corrective Action/Issue Management

C-1 
WHC-EP-0907 REV.0

APPENDIX D

\section{REQUIRED FIELDS FOR HATS DOCUMENT}

\section{Initiating Document}

Originating Document Number

Class

Title

Originating Contractor

Originator

Responsible Person

Abstract Text

\section{Condition Document}

Condition Number

Type

Condition Title

View

Owner

Closure

Abstract Text

\section{Action Number}

Action Number

Action Title

Owner

Closure

Abstract Text

D-1 
THS PAGE INTENTIONALLY IEFT BLANK. 


\section{CORRESPONDENCE DISTRIBUTION COVERSHEET}

M. K. Britton, 376-2448

Distribution

Subject: CORRECTIVE ACTION MANAGEMENT (CAM) PROCESS GUIDE

\section{INTERNAL DISTRIBUTION}

\begin{tabular}{|c|c|c|c|c|}
\hline Approval & Date & Name & Location & w/att \\
\hline & & Correspondence Control & A3-01 & \\
\hline & & J. R. Akridge & H8-60 & \\
\hline & & R. B. Balthazor & B3-55 & \\
\hline & & G. E. Bentley & $\mathrm{HO}-15$ & \\
\hline & & M. K. Britton & B3-56 (5 copies) & \\
\hline & & J. M. Clifford & G1-67 & \\
\hline & & J. McCoy & H6-23 & \\
\hline & & N. P. Daniel & T4-05 & \\
\hline & & C. L. Day-Phalen & $\mathrm{R} 2-52$ & \\
\hline & & A. R. Hawkins & B3-55 & \\
\hline & & M. L. Heinemeyer & T3-01 & \\
\hline & & C. K. Kasch & A5-55 & \\
\hline & & T. J. Kelly & T7.37 & \\
\hline & & W. C. Kious & $\mathrm{N} 2-13$ & \\
\hline & & G. A. Lovejoy & A3-05 & \\
\hline & & P. A. Martens & B4-49 & \\
\hline & & S. M. McInturff & $\mathrm{H} 1-77$ & \\
\hline & & A. K. McKay & B1-11 & \\
\hline & & G. C. Mooers & R3-11 & \\
\hline & & J. L. Pfeiffer & A5-55 & \\
\hline & & J. G. Phelps & T6-07 & \\
\hline & & J. B. Reiten & B1-11 & \\
\hline & & C. F. Schuster & S6-19 & \\
\hline & & D. A. Severin & $\mathrm{S} 2-42$ & \\
\hline & & K. M. Thomson & T5-51 & \\
\hline & & J. E. Van Erem & X3-78 & \\
\hline & & W. V. Witherspoon & N2-13 & \\
\hline & & P. A. Yourdan & S6-65 & \\
\hline
\end{tabular}


THS PAGE MTEUTIONALLY LEFT BLANK. 